\title{
Influence of Thermal Ageing and Specimen Size on Fracture Toughness of Z3CN20-09M Casting Duplex Stainless Steels
}

\author{
Yu Wang, Yaohong Yao*, Zhengpin Wang, Yaohua Jin, Yuyu Gao, Nan Cao and Jiangnan Liu \\ Shaanxi Provincial Key Laboratory of Photoelectric Functional Materials and Devices, \\ Xi'an Technological University, Xi'an 710032, P. R. China
}

To assess the thermal aging embrittleness of the primary coolant pipes in pressurized water reactor (PWR), the fracture toughness test is conducted for Z3CN20-09M CDSSs thermally aged at $400^{\circ} \mathrm{C}$ for $10,000 \mathrm{~h}$ and the fracture morphologies of the virgin and the aged specimen are analyzed based on SEM technique. The influence of the specimen thickness and thermal ageing time on the fracture toughness of the material is discussed in details. The results show that with increasing thermal ageing time, the $J_{I C}$ of Z3CN20-09M CDSSs significantly decreases and the fracture mechanism transits from the ductile microvoid coalescence fracture to the cleavage fracture in ferrite and the quasi-cleavage fracture in austenite. Moreover, the theoretical expression between the fracture toughness $K_{C}$ and the specimen thickness $t$ of Z3CN20-09M CDSSs is established, which can be used to estimate the fracture toughness with different specimen thickness. [doi:10.2320/matertrans.M2017345]

(Received December 5, 2017; Accepted March 28, 2018; Published April 27, 2018)

Keywords: casting duplex stainless steel, thermal ageing embrittleness, fracture toughness, size effect, spinodal decomposition

\section{Introduction}

Casting duplex (austenitic-ferritic) stainless steels (CDSSs) (e.g. CF3, CF8, CF3A, CF8A, Z3CN20-09M) are generally used in the pressurized water reactor (PWR) nuclear power plant to manufacture the primary pressure boundary components, such as pipes, valves and flanges, in view of their excellent mechanical properties, good weldability, sound castability and high resistance to stress corrosion cracking. ${ }^{1-5)}$ Many literatures have confirmed that the presence of a certain volume of ferrite distributed in the austenitic matrix has two effects on CDSSs: (i) a positive level effect on the weldability, yield strength and tensile strength, stress corrosion cracking and intergranular corrosion resistant of the austenitic steel, and (ii) a negative effect on thermal aging embrittlement of CDSSs after long time service at the reactor operating temperatures in the range of 288 to $327^{\circ} \mathrm{C} .{ }^{1,4-9)}$ Moreover, some works have demonstrated that when the operating temperature is above $250^{\circ} \mathrm{C}$, the thermal aging embrittlement phenomenon will occur and the associated microstructure mainly changes in the ferrite phase. ${ }^{4,5)}$ Previous works have reported that various carbide phases and intermetallic compounds, such as sigma and chi-phase, G-phase and the chromium-enriched alpha prime phase $\left(\alpha^{\prime}\right)$, can precipitate in the ferrite phase during long time service at elevated temperatures, and that the main cause of thermal aging brittleness in the steels is the formation of $\mathrm{Cr}$-rich $\alpha^{\prime}$ phase by spinodal decomposition in ferrite phase. ${ }^{1,6,7,9-12)}$ In addition to an increase in hardness, yield strength, tensile strength, thermal aging brittleness also results in a great decrease in plasticity, impact property and fracture toughness. ${ }^{4-7,12)}$

Fracture toughness is a very important parameter directly related to structural integrity of the components, which is applicable to fracture control and to fracture test in measuring the material property for a crack to resist fracture. ${ }^{13-19)}$ Many investigators have conducted the artificially accelerated ageing experiments to assess the thermal ageing embrittleness on the fracture toughness of CDSSs including CF8M,

*Corresponding author, E-mail: yyhong0612@yahoo.com
316LN and TP304L, which have verified that the fracture toughness decreases with the accelerating thermal ageing time. ${ }^{2,3,15,17,19)}$ The reduction of fracture toughness ultimately leads to the catastrophic structural failure and the loss of coolant accident (LOCA), both of which can cause a functional operation cessation of a nuclear power plant and possible exposure of the public to radiation.

The primary pipes are made by Z3CN20-09MCDSSs, followed by the French RCC-M Specification (RCC-M, 2000), which have been safely served for more than 20 years in China nuclear power plant. The microstructure evolution, tensile and impact properties and SPT (small punch test) properties of Z3CN20-09M CDSSs have been reported in details with the long term thermal ageing time. ${ }^{6,7)}$ However, the knowledge on the fracture toughness of Z3CN20-09M CDSSs with the extended thermal ageing time is still limited. In this paper, Z3CN20-09M CDSSs are accelerately heated at $400^{\circ} \mathrm{C}$ up to $10,000 \mathrm{~h}$, corresponding to the actual service life of about 36.4 years, the fracture toughness of thermally aged Z3CN20-09M CDSSs and effects of the thermal ageing embrittlement are investigated and the influence of the specimen size on the fracture toughness is also reported.

\section{Experimental Procedure}

The nominal chemical compositions of Z3CN20-09M CDSSs with the $\delta$-ferrite content of $\sim 15 \%$ are listed in Table 1. Z3CN20-09M CDSSs are accelerately heated in the electric pit-type heating furnace (RJ2-55-6, China) at $400^{\circ} \mathrm{C}$ for $3,000 \mathrm{~h}$ and $10,000 \mathrm{~h}$. The ageing effect at $400^{\circ} \mathrm{C}$ for 3,000 and $10,000 \mathrm{~h}$ individually equals to that of 10.9 and 36.4 years at the service temperature (i.e. $290^{\circ} \mathrm{C}$ ) according to Arrhenius equation as in eq. (1): ${ }^{20)}$

$$
t_{1} / t_{2}=E X P\left[Q / R\left(1 / T_{1}-1 / T_{2}\right)\right]
$$

Table 1 Chemical composition of Z3CN20-09M CDSSs (mass\%).

\begin{tabular}{rlllllllll}
\hline Material' & $\mathrm{C}$ & $\mathrm{Mn}$ & $\mathrm{Si}$ & $\mathrm{S}$ & $\mathrm{P}$ & $\mathrm{Cr}$ & $\mathrm{Ni}$ & $\mathrm{N}$ & $\mathrm{Fe}$ \\
\hline Z3CN20-09M & 0.03 & 1.14 & 1.25 & 0.06 & 0.03 & 20.80 & 8.68 & 0.03 & Bal. \\
\hline
\end{tabular}



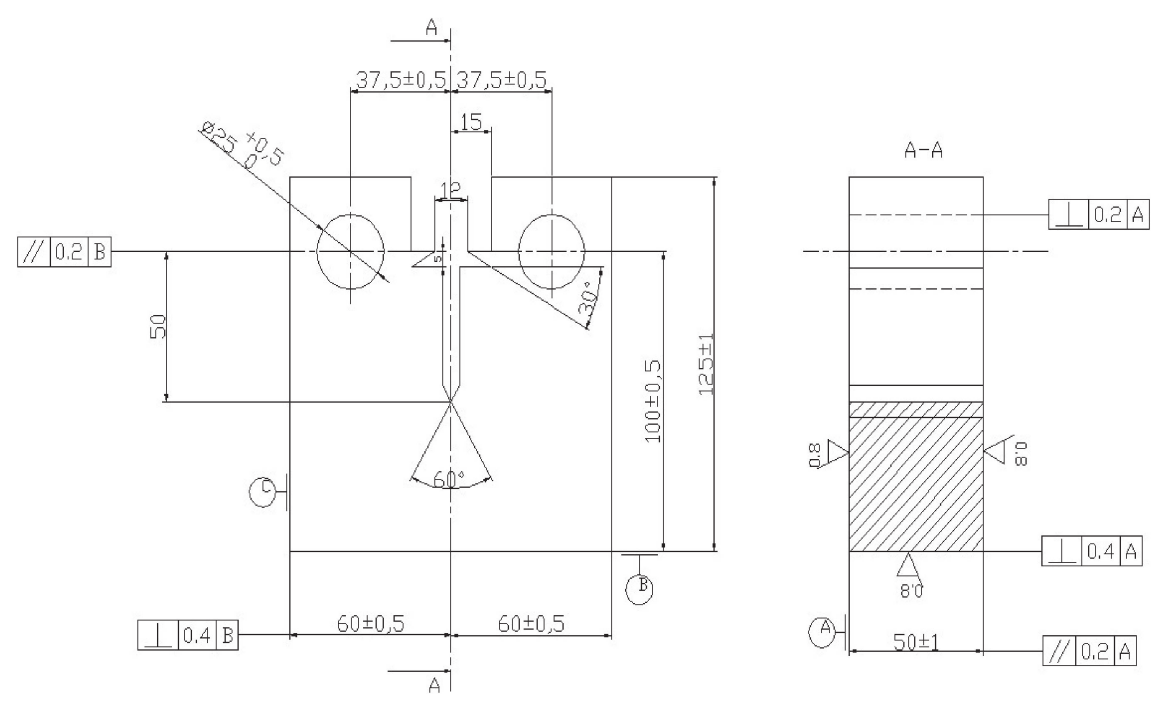

Fig. 1 Geometry of the CT specimen (unit: $\mathrm{mm}$ ).

Table 2 Mechanical properties of Z3CN20-09M CDSSs at room temperature.

\begin{tabular}{ccccccc}
\hline & $R_{p 02} / \mathrm{MPa}$ & $R_{m} / \mathrm{MPa}$ & $Z / \%$ & $A / \%$ & $E / \mathrm{GPa}$ & $\mu /-$ \\
\hline $0 \mathrm{hrs}$ & 246.7 & 524.7 & 78.9 & 61.1 & 195.0 & 0.28 \\
$3,000 \mathrm{hrs}$ & 279.0 & 634.2 & 66.7 & 51.9 & - & - \\
$10,000 \mathrm{hrs}$ & 279.1 & 645.2 & 63.3 & 50.2 & - & - \\
\hline
\end{tabular}

where $t_{1}$ and $t_{2}$ are the service time at the temperature $T_{1}$ and $T_{2}$, respectively, $Q$ is Arrhenius activation energy, and $R$ is the gas constant. Moreover, the mechanical properties of Z3CN20-09M CDSSs are given in Table 2, according to the previous study, ${ }^{6)}$ where $R_{p 0.2}, R_{m}, Z, A, E$ and $\mu$ are denoted as yield strength in $\mathrm{MPa}$, tensile strength in MPa, percentage of area reduction, percentage elongation, elastic modulus in GPa and Poisson ratio, respectively. Microstructures of the unaged and the aged specimens are analyzed by use of transmission electron microscope (TEM, JEM-200CX, Japan).

According to ASTM E1820, ${ }^{21)}$ the $J$-integral fracture toughness experiments are conducted in the fatigue test machine (MTS810, USA) with a servo hydraulic testing systems and a maximum capacity of $100 \mathrm{kN}$. To investigate the effect of the specimen thickness on the fracture toughness, the compact tension (CT) specimens of the unaged materials are chosen with the thickness of 12, 20, 30,40 and $50 \mathrm{~mm}$ fabricated from the unaged and aged materials following ASTM E399. ${ }^{22}$ ) The thickness of CT specimens for $\mathrm{J}_{\mathrm{IC}}$ employed in the experiments is $50 \mathrm{~mm}$ and the detailed shape and dimension of the specimen with the thickness of $50 \mathrm{~mm}$ are shown in Fig. 1. Fatigue precracking is carried out at room temperature and the crack length $(a)$ must satisfy the requirement of ASTM E399, i.e. $a / W$ (crack length/specimen width) is in the range of $0.45-0.60$. After the $J$-integral fracture toughness experiment, fracture morphologies of samples are examined by scanning electron microscopy (SEM, TESCAN XM5136, Czech).

\section{Results and Discussions}

\subsection{Size effect on fracture toughness $K_{C}$}

Figure 2 shows the characteristic relationship between the $J$-integral of the virgin specimen with different thicknesses.

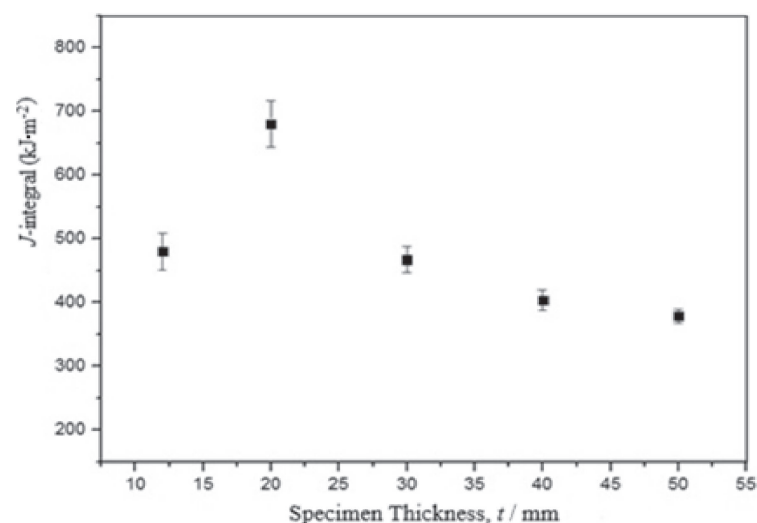

Fig. 2 Evolution of the J-integral with respect to the thickness of the virgin specimen.

It can be seen that, with increasing specimen thickness, the $J$-integral firstly increases to the peak value at the thickness of $20 \mathrm{~mm}$ and then gradually decreases to a certain value at the thickness of $50 \mathrm{~mm}$. The same tendency in the $J$-integral is qualitatively typical for high strength metals and also corresponds to the fracture behavior of the specimen changes from the plane stress state in thin thickness to the plane strain state in thick thickness. ${ }^{16)}$ If the specimen is thick enough, the fracture toughness is independent to the specimen thickness, which is called plane strain fracture toughness $K_{I C}$. In general, a $K-R$ curve is equivalent to a $J-R$ curve for an elastic material, which can be expressed as: ${ }^{19)}$

$$
K_{I C}=\left(E J_{I C} / 1-\mu^{2}\right)^{1 / 2}
$$

where $E$ and $\mu$ denotes the elastic modulus and Poisson ratio, respectively. The $E$ and $\mu$ of Z3CN20-09M CDSSs are listed in Table 2.

Figure 3 displays the relationship between the fracture toughness $K_{C}$ and the specimen thickness $t$ of Z3CN20-09M CDSSs. Yang et al. ${ }^{23)}$ and Weiss and Yukawa ${ }^{24)}$ have investigated the mathematical model between $K_{C}$ and $t$. For the material in complete plane stress state, i.e., $t \rightarrow 0$, the theoretical expression is expressed as:

$$
K_{C}=\xi t^{\frac{1}{2}}
$$




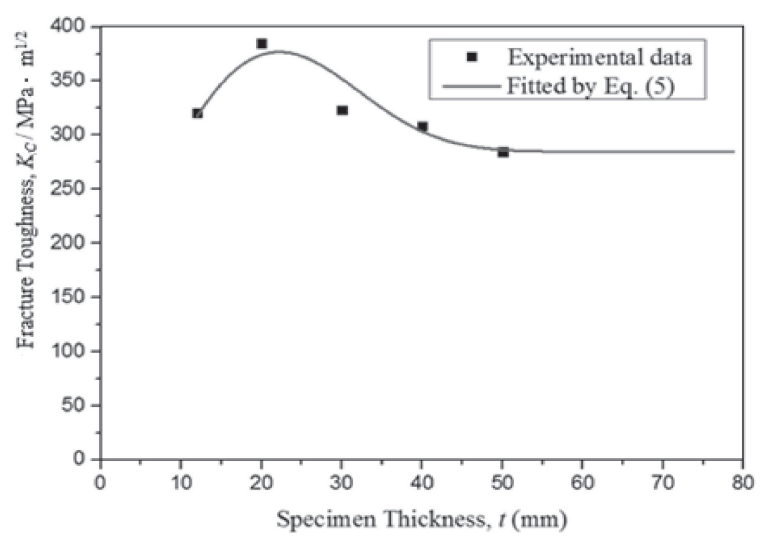

Fig. 3 Relationship between the fracture toughness $K_{C}$ and the specimen thickness $t$.

where $\xi$ is the material constants. For a specimen with various thicknesses, Yang et $a l^{23}$ ) have established a theoretical expression in qualitative agreement with experiment, given by:

$$
K_{C}=\xi t^{\frac{1}{2}} e^{-k t}+K_{I C}\left(1-e^{-k t}\right)
$$

where $\xi$ and $k$ are the material constants. For eq. (4), if $t \rightarrow 0$, $e^{-k t} \rightarrow 1, \quad\left(1-e^{-k t}\right) \rightarrow 0$, then $K_{C} \rightarrow \xi t^{\frac{1}{2}} ; \quad$ if $t \rightarrow \infty$, $e^{-k t} \rightarrow 0,\left(1-e^{-k t}\right) \rightarrow 1$, then $K_{C} \rightarrow K_{I C}$. Thus eq. (4) is proper to express the relationship between $K_{C}$ and $t$ in various stress states.

By using the least-square fitting for the experimental data in Fig. 3, the regression equation between $K_{C}$ and $t$ is obtained as:

$$
K_{C}=92.16 t^{\frac{1}{2}} \mathrm{e}^{-4 \times 10^{-5} t^{3}}+284.6\left(1-e^{-4 \times 10^{-5} t^{3}}\right)
$$

It can be seen from Fig. 3 that when the specimen thickness is $30 \mathrm{~mm}$, the maximum relative error is $\sim 6.01 \%$ between the experimental data and the fitted value, and that the regression line is fully flat when the specimen thickness is over $50 \mathrm{~mm}$, indicating that the specimen is completely in the plane strain state. Therefore, it is suitable to measure the fracture toughness $\left(J_{I C}\right.$ or $\left.K_{I C}\right)$ of the specimen with a thickness of $50 \mathrm{~mm}$.

\subsection{Effect of thermal aging on fracture toughness $\left(J_{I C}\right)$}

After investigating the effect of the specimen thickness on the fracture toughness of the virgin materials, $J$-integral fracture toughness tests of the virgin and aged Z3CN20-09M CDSSs have been performed with CT specimens in $50 \mathrm{~mm}$ thick at room temperature by single specimen unloading compliance technique. $J$ versus $\Delta a$ graphs are plotted by load versus load line displacement (COD measurements) data. The $J$-resistance curve ( $J$ - $R$ curves) obtained for virgin and aged specimens as well as corresponding power law regression curves are shown in Fig. 4. As seen in Fig. 4, a blunting construction line, $J=\left(2 \sigma_{f s}\right) \Delta a$, is plotted, where the flow stress, $\sigma_{f s}$ can be determined according to Table 2 by $\sigma_{f s}=\left(R_{p_{0.2}}+R_{m}\right) / 2$. Furthermore, exclusion lines are drawn at $0.15 \mathrm{~mm}$ and $1.5 \mathrm{~mm}$ of crack extension $(\Delta a)$ parallel to the blunting line, where the $J-\Delta a$ data points are valid data to fit the power law regression curve. The $J$ integral fracture toughness $\left(J_{0.2}\right)$ value is determined by the intersection between the $J-R$ regression curve and a $0.2 \mathrm{~mm}$ offset line. If the net thickness of the specimen, $B_{N}$, satisfies (a)

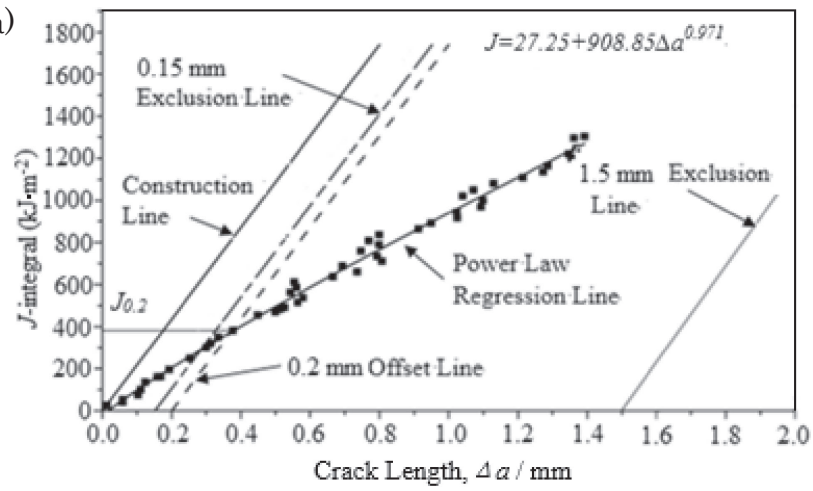

(b)

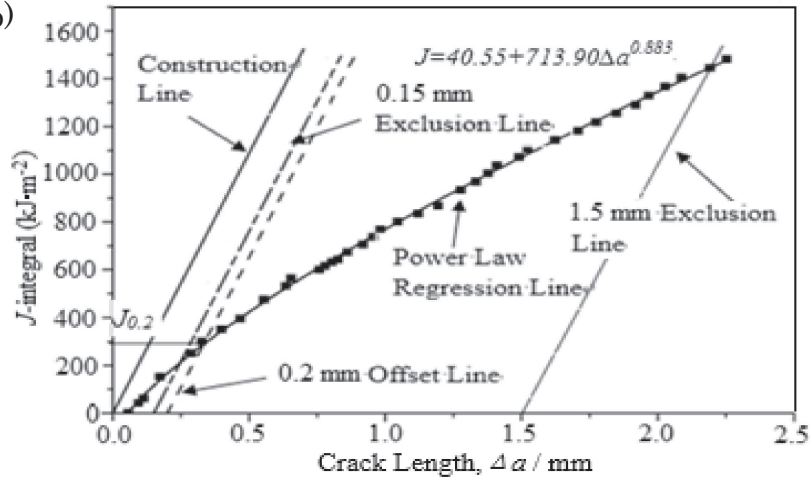

(c)

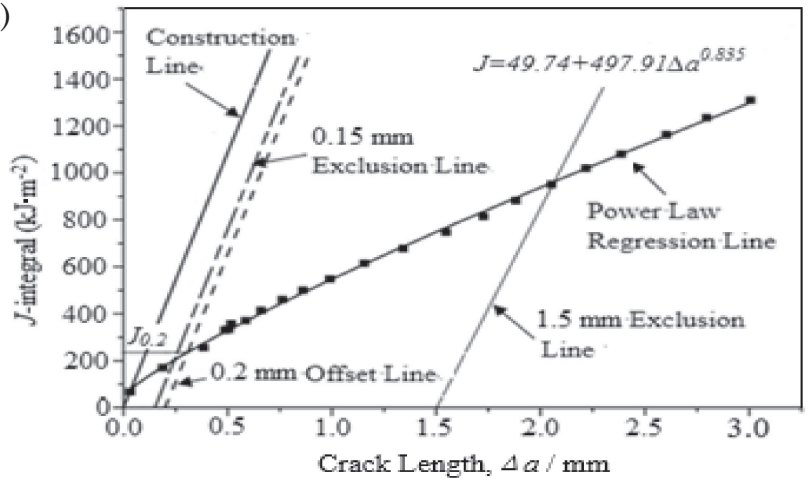

Fig. $4 J$-resistance curves ( $J-R$ curves) for the virgin and aged specimens (a) virgin; (b) aged for $3,000 \mathrm{~h}$; (c) aged for $10,000 \mathrm{~h}$.

the size requirement of $B_{N} \geq 25 J_{0.2} / \sigma_{f s}$, the qualification criteria, $J_{0.2}=J_{I C}$, are met. As noted in the Fig. 4 , the $J_{I C}$ value obtained from the virgin and the aged specimen for $3,000 \mathrm{~h}$ and $10,000 \mathrm{~h}$ is $378.6 \mathrm{~kJ} \mathrm{~m}^{-2}, 291.4 \mathrm{~kJ} \mathrm{~m}^{-2}$ and $234.5 \mathrm{~kJ} \mathrm{~m}^{-2}$, respectively. Compared with that of the virgin specimen, the $J_{I C}$ value of the aged specimen individually decreases by $23.03 \%$ for $3,000 \mathrm{~h}$ and $38.06 \%$ for $10,000 \mathrm{~h}$. It has been confirmed that the thermal aging effect is a reduction in the fracture toughness of the material as a function of time and the magnitude of the reduction depends upon the type of casting method, the material chemistry, and the microstructure changes in service. ${ }^{25)}$ Figure 5 shows the substructure evolution in the ferrite phase of Z3CN20-09M CDSSs aged at $400^{\circ} \mathrm{C}$ for $0 \mathrm{~h}, 3,000 \mathrm{~h}$ and $10,000 \mathrm{~h}$. Compared with Fig. 5(a), it can be obviously seen in Fig. 5(b) that the spinodal decomposition starts to occur in the ferrite phase of Z3CN20-09M CDSSs aged at $400^{\circ} \mathrm{C}$ for $3,000 \mathrm{~h}$, and that the mottled contrast in Fig. 5(c) has been clearly observed in the spinodally-decomposed microstructure in which the dark and light gray zones is correspond 


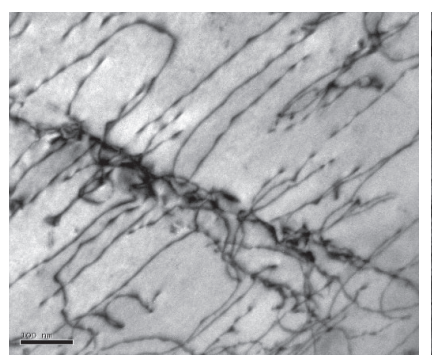

(a)

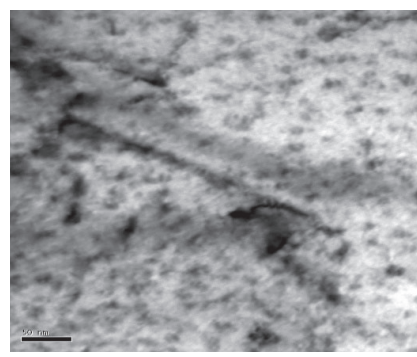

(c)

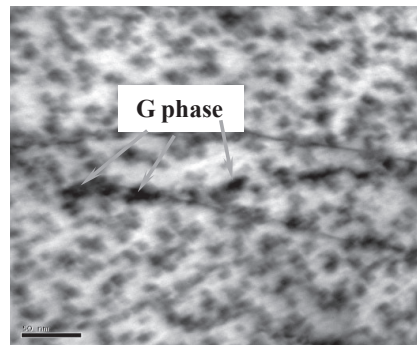

(e)

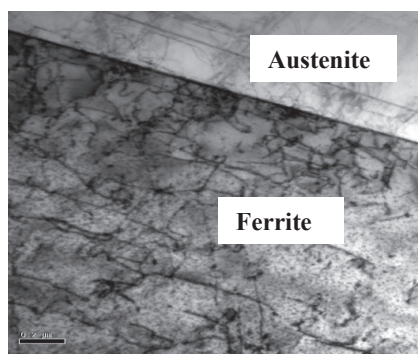

(b)

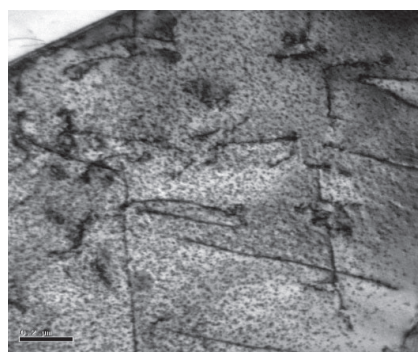

(d)

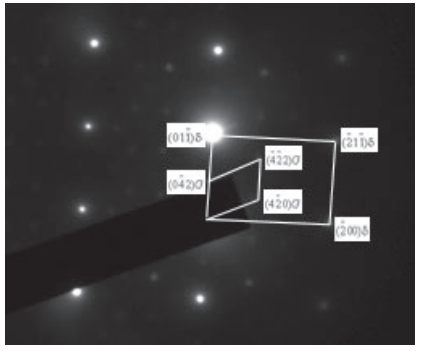

(f)
Fig. 5 Substructure in ferrite phase of Z3CN20-09M CDSSs aged for different times. (a) $0 \mathrm{~h}$; (b) 3,000 h; (c) Detail view of (b); (d) 10,000 h; (e) Detail view of (d); (f) Diffraction spots of $G$ phase.

to the Cr-rich $\alpha^{\prime}$ phase and Fe-rich $\alpha$ phase, respectively. Moreover, it can also be seen in Fig. 5(b) that the spinodal decomposition first takes place in the center of the ferrite phase and the spinodally-decomposed microstructure has not been observed in the ferrite phase near the ferrite/austenite phase boundary. Previous study has reported that the spinodal decomposition in ferrite phase can result in the thermal ageing brittleness of CDSSs, such as CF3A, CF8A, which will cause an increase in hardness, yield strength, tensile strength and a decrease in plasticity, impact property and fracture toughness. ${ }^{4-7)}$ So the formation of Cr-rich $\alpha^{\prime}$ phase by spinodal decomposition is mainly responsible for the rapid decrease of $J_{I C}$ value of the aged specimen for $3,000 \mathrm{~h}$. When the accelerated thermal ageing time increases from $3,000 \mathrm{~h}$ to $10,000 \mathrm{~h}$, the spinodally-decomposed microstructures become coarsening (Fig. 5(d)) and the G-phases are precipitated on the dislocation lines in ferrite phase, as shown in Fig. 5(e). The corresponding diffraction pattern in Fig. 5(f) reveals that the G-phase is of FCC structure with the lattice parameter of $1.12 \mathrm{~nm}$. Some literatures ${ }^{27,28)}$ and the previous study $\left.{ }^{6}\right)$ have reported that the $\mathrm{Ni}$ - and Si-rich $\mathrm{G}$ phase is oriented cube-on-cube with the ferrite and its formation has a great agreement with the spinodal decomposition in ferrite. It is the coarsening of the spinodally-decomposed microstructure and the precipitation of $\mathrm{G}$ phase in ferrite phase that mainly make the $J_{I C}$ value further decrease from $291.4 \mathrm{~kJ} \mathrm{~m}^{-2}$ to $234.5 \mathrm{~kJ} \mathrm{~m}^{-2}$.

\subsection{Fracture morphology}

The fracture surfaces of the virgin and aged specimens in the crack propagation zone are presented in Fig. 6 . It can be found from Fig. 6(a) that the fracture surface of the virgin specimen is almost full of the deep and well-defined dimple structure including empty dimples and those holding small particles in the irregular and spherical shape, which is a typical fracture feature of high toughness materials. So the fracture mechanism of the virgin specimen is intrinsically the microvoid coalescence ductile fracture predominated by the nucleation, growth and coalescence of the microdimples. However, in the fracture surface of the aged specimen for $3,000 \mathrm{~h}$, about $10 \% \sim 15 \%$ of the surface is the quasi-cleavage zone corresponding to the ferrite phase, and the remainder exhibits ductile dimple morphology in the austenite phase, as shown in Fig. 6(b). It is demonstrated that the ferrite phase in the specimen aged at $400^{\circ} \mathrm{C}$ for $3,000 \mathrm{~h}$ becomes thermal ageing brittle mainly due to the formation of Cr-rich $\alpha^{\prime}$ phase by spinodal decomposition (Fig. 5(b)), which leads to increasing of microhardness of the ferrite phase. Some literatures have confirmed that thermal aging embrittlement in duplex stainless steels manifests itself microstructurally as a combination of precipitation/growth of carbides, nitrides in the boundaries between the ferrite and austenite phases, and the deleterious changes in the cleavage fracture resistance of the ferrite phase itself. ${ }^{4,5,26)}$

For the brittle ferrite phase with the ageing time shown in Fig. 6(c), it can be seen that the cracks preferentially propagate along the ferrite phase and the phase boundary between the austenite and the ferrite. Compared with those of the virgin specimen, both the size and the number of dimples decrease in fracture surface of the aged specimen for 3,000 h. As indicated in Fig. 6(d), when the thermal ageing time is up to $10,000 \mathrm{~h}$, for the coarsening of the spinodally-decomposed microstructures as well as the formation of the G-phases in ferrite phase (Fig. 5(e)), the cleavage-like area increases to $\sim 20 \%$, which is almost the same with content of the ferrite in Z3CN20-09M CDSSs. Meanwhile, the cleavage morphology region starts to emerge the river patterns with the characteristic of brittle fracture. In the ductile austenite zone, a steady decline of the size and the number of the dimples appears. For the dislocation configuration evolution, the fractography in austenite changes from dimple pattern to mixed fracture with dimple and tear ridges. So fractographic examination shows that the reduction of fracture toughness with the ageing time is associated with a fracture mechanism transition from ductile microvoid coalescence to the mixed fracture with the cleavage steps and the tear ridges, which mainly result from the combination of the precipitation of additional phases in the ferrite phase, involving the formation of a Cr-rich $\alpha^{\prime}$ phase by spinodal decomposition, and the precipitation of a Ni- and Si-rich $\mathrm{G}$ phase.

\section{Conclusion}

(1) Mainly for the spinodal decomposition, the precipitation of the G-phase and the coarsening of the spinodally-decomposed structure, fracture toughness $J_{I C}$ of Z3CN20-09M CDSSs significantly decreases with increasing thermal ageing time. 


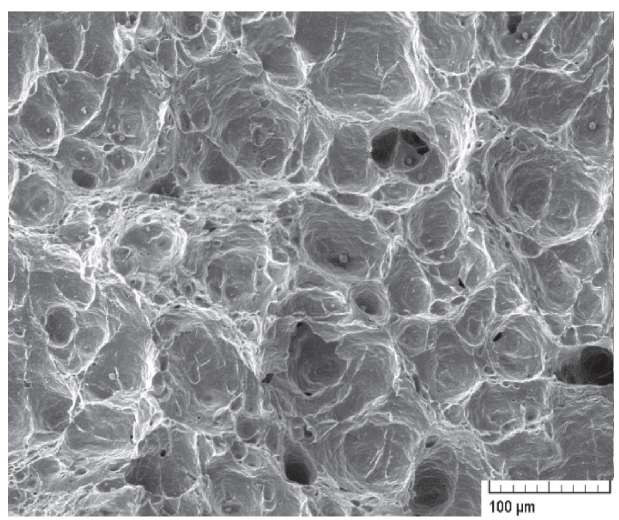

(a)

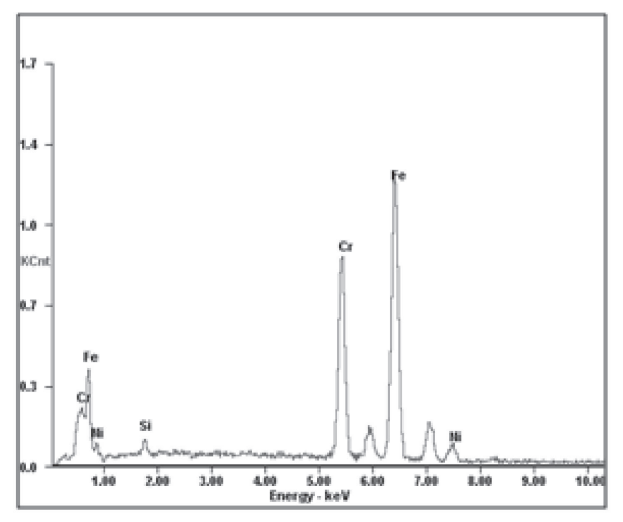

(c)

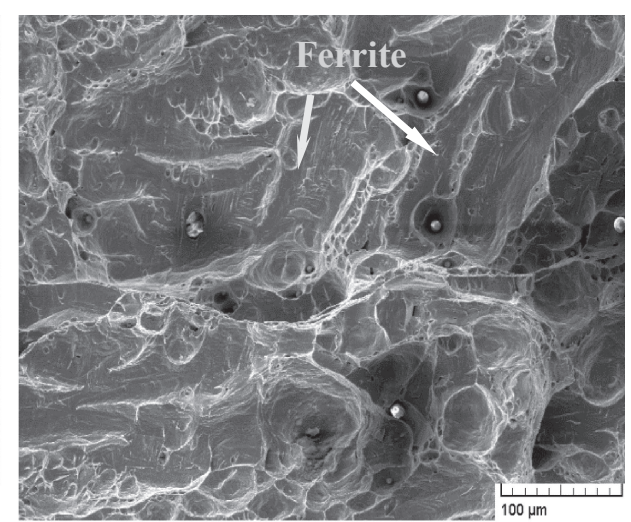

(b)

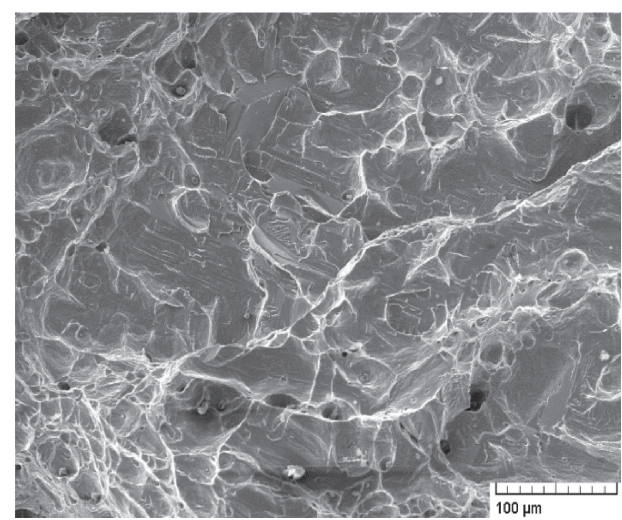

(d)

Fig. 6 Scanning electron micrographs in fracture surface of the virgin and aged specimens. (a) virgin; (b) aged for $3000 \mathrm{~h}$; (c) EDX analysis for Ferrite zone in (b); (d) aged for 10,000 h.

(2) The theoretical expression between the fracture toughness $K_{C}$ and the specimen thickness $t$ of Z3CN20-09M CDSSs has been obtained, showing that the estimated fracture toughness $K_{I C}$ is valid when the specimen thickness is over $50 \mathrm{~mm}$.

(3) The fracture toughness of Z3CN20-09M CDSSs reduces with the ageing time, which is associated with a fracture mechanism transition from ductile microvoid coalescence to the mixed fracture with the cleavage plane and the tear ridges.

\section{Acknowledgments}

This work was supported by the National Science Foundation of China (grant no. 51371132) and the Open Foundation of Shaanxi Provincial Key Laboratory of Photoelectric Functional Materials and Devices (Contract No. 2015SZSj-59-7).

\section{REFERENCES}

1) S. Cicero, J. Setién and I. Gorrochategui: Nucl. Eng. Des. 239 (2009) $16-22$.

2) O.H. Ibrahim, I.S. Ibrahim and T.A.F. Khalifa: J. Mater. Sci. Technol. 26 (2010) 810.

3) J.D. Kwon, J.H. Ihn, J.C. Park and S.J. Choi: KSME Int. J. 16 (2002) 902.

4) O.K. Chopra and H.M. Chung: Nucl. Eng. Des. 89 (1985) 305.

5) H.M. Chung: Int. J. Pressure Vessels Piping 50 (1992) 179
6) Y.H. Yao, J.F. Wei and Z.P. Wang: Mater. Sci. Eng. A 551 (2012) 116

7) S.L. Li, Y.L. Wang and X.T. Wang: Mater. Sci. Eng. A 625 (2015) 186.

8) T. Yamada, S. Okano and H. Kuwano: J. Nucl. Mater. 350 (2006) 47.

9) M.D. Mathew, L.M. Lietzan, K.L. Murty and V.N. Shah: Mater. Sci. Eng. A 269 (1999) 186.

10) J.J. Shiao, C.H. Tsai, J.J. Kai and J.H. Huang: J. Nucl. Mater. 217 (1994) 269.

11) M. Hättestrand, P. Larsson, G. Chai, J.O. Nilsson and J. Odqvist: Mater. Sci. Eng. A 499 (2009) 489.

12) A. Trautwein and W. Gysel: ASTM Spec. Tech. Publ. 756 (1982) 165.

13) X.K. Zhu and J.A. Joyce: Eng. Fract. Mech. 85 (2012) 1.

14) W.F. Lu, C.L. Lai and J.Y. Huang: Mater. Trans. 55 (2014) 506.

15) B.S. Dutt, G. Shanthi, G. Sasikala, M.N. Babu, S. Venugopal, S.K. Albert, A.K. Bhaduri and T. Jayakumar: Procedia Eng. 86 (2014) 302.

16) Y. Tanabe: Mater. Trans. 54 (2013) 314

17) J.M. Koo, S. Park and C.S. Seok: Nucl. Eng. Des. 259 (2013) 198.

18) Z.Y. Cui, Z.Y. Liu, L.W. Wang, C.W. Du and X.G. Li: Mater. Trans. 56 (2015) 777.

19) G. Sasikala and S.K. Ray: J. Nucl. Mater. 408 (2011) 45.

20) A.D. McNaught and A. Wilkinson (Eds.): 2nd Ed. Blackwell Scientific Publications. 1997.

21) American Society for Testing of Materials: ASTM E1820-11e2. Pennsylvania: ASTM Inter-national, 2011.

22) American Society for Testing of Materials: ASTM E399-12e3. Pennsylvania: ASTM Inter-national, 2012.

23) J.Y. Yang and X. Zhang: J. Mech. Strength. 25 (2003) 076.

24) V. Weiss and S. Yukawa: ASTM Spec. Tech. Publ. 381 (1965) 1.

25) O.K. Chopra: NUREG/CR-4513, ANL-93/22, 1994.

26) O.K. Chopra: NUREG/CR-4744, ANL-92/42, 1993.

27) J. Bentley and M.K. Miller: Mater. Res. Symp. Proc. 82 (1987) 163.

28) J.M. Vitek, S.A. David, D.J. Alexander, J.R. Keiser and R.K. Nanstad: Acta Metall. 39 (1991) 503. 